\title{
Design and optimization of industrial woody biomass pretreatment addressed by DryKiln_CRP, a multiscale computational model: particle, bed and dryer levels
}

\author{
J. Colin ${ }^{1 *}$, R. Rémond ${ }^{2}$, P. Perré ${ }^{1}$ \\ ${ }^{1}$ LGPM, CentraleSupélec, Université Paris-Saclay \\ Grande Voie des Vignes, Châtenay-Malabry, 92295, France \\ ${ }^{2}$ Université de Lorraine, LERMAB, ENSTIB \\ 27, rue Philippe Séguin, Épinal, 88026, France \\ *Corresponding author: Tel.:+331411310 04, E-mail: julien.colin@centralesupelec.fr
}

\begin{abstract}
Thermochemical conversion processes of biomass to energy are increasingly demanding in terms of the quality of the raw material, especially regarding its moisture content. The use of continuous dryers is attractive because of their low cost and ease of integration into the production line. However, the design of the drier (drying chamber and heating source) and the optimization of its control based on relevant criteria are complex.
\end{abstract}

This paper presents DryKiln_CRP, a comprehensive multiscale model able to account for the two-way interactions between particles, bed and drier. The drying model at the particle level is based on the van Meel approach which was extended to account explicitly for heat and mass transfer coupling. Computational simulations are discussed for two case studies in order to emphasize the potential of this multiscale computational model in the design and optimization of industrial plants devoted to the pretreatment of biomass.

Keywords: biomass pretreatment, wood energy, continuous dryers, multiscale modelling, design and optimization.

\section{INTRODUCTION}

The bioeconomy - i.e. the use of biomass for food, feed, industrial and energy purposes [1] - has the potential to contribute to a more sustainable use of resources. In particular, the bioeconomy has a positive effect to reduce 
global warming, and lower the energy dependence of France. In this context, thermochemical conversion processes are promising for a wide range of applications such as heat, biomolecules or biofuels production [2]. These dry conversion routes require increasingly high quality of the raw materials, particularly regarding moisture content $(M C)$. The use of continuous convective dryers for the pretreatment of wood energy is attractive because of their low operating cost and their ease of integration in the production line.

However, the use of such dryers is not without pitfall. For example, heterogeneity of the climatic conditions inside the dryer, together with biomass variability, make the conception and optimization of these industrial plants complex. Identifying the best technical solutions and estimating their gains through empirical knowledge may be costly in both time and money. Simulation models may therefore be useful tools, either for optimal design or for on-line control of industrial plants. However, the various spatial scales involved in such processes, together with the huge variability of biomass, render such a modeling approach challenging.

At the dryer scale, the air parameters change along the flow. This profile of climatic conditions depends on the heat and mass transfer at the exchange surfaces - wood particles and wall of the dryer - and vice versa: the relative humidity $(R H)$ and temperature of the air affect the drying rate of each particle. Therefore the two-way coupling between two spatial scales (particle $\leftrightarrow$ dryer) must be understood in order to simulate the continuous drying of a bed of wood particles [3, 4]. Some numerical approaches use the concept of distributed micro-models. It allows the two-way coupling to be comprehensive even when all particles are different. Thus it is possible to assess the dryer performance for reducing the heterogeneity of final $M C$ of particles, in spite of the initial variability.

Inside the biomass particle, Finite Element or Control Volume based computational models are very efficient in predicting the evolution of the variable fields (temperature, $M C$, pressure, strain, stress). They are also well adapted to deal with non-linearities and couplings, and for testing various formulations or parameter values. In this sense, they are able to provide predictive simulations, and can also assist the improvement of the fundamental understanding [5-8]. As drawbacks, this approach usually leads to significant computational times, which limits the total number of particles at the drier scale. In addition, particular phenomena such as the effect of checks on transfer are difficult to consider. That is why analytical models [9-11] are often employed to simulate the drying of a large number of particles, as it is the case for the pretreatment of biomass. The concept of characteristic drying curve defines the drying rate as a proportion of the maximum drying rate which is obtained during the so-called constant drying rate (CDR) period, when the entire exchange surface is supplied with free water. This proportion is a dimensionless function of $M C$. However, a usual assumption in the 
approach proposed by van Meel [11] is that all of the energy supplied to the sample is used to evaporate water. This strong assumption leads to a poor agreement between the simulations and the experimental results during certain drying periods, namely during transient periods such as heating-up or during variable drying conditions $[9,12]$. Without considering the sensible heat, such models can neither faithfully simulate the evolution of wood $M C$ if the airflow temperature varies, as it does along the tunnel of drying, nor predict the phenomena of condensation or heating-up.

This paper proposes DryKiln_CRP, a multiscale computational model to design and optimize industrial convective dryers used for wood energy pretreatment. The physical formulation of this model at the particle and the dryer scale is presented in the following part. Then the relevance of the multiscale model as an operational tool will be illustrated via two case studies: the optimization of a fixed-bed dryer and, the design of a conveyor dryer. These dryers may involve simple - parallel- and counter-flow - or combined airflow configurations.

\section{AN INTERACTIVE, FLEXIBLE AND REALISTIC MULTISCALE MODEL}

At the particle scale: an extended van Meel model

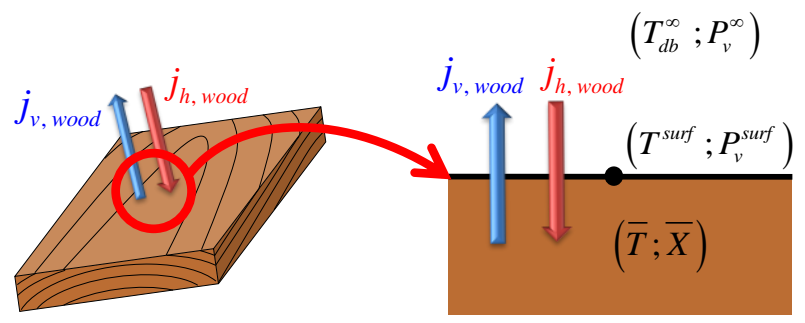

Fig. 1. Heat and mass fluxes at the surface of the particle

The local model predicts the evolution of the parameters of a wood particle ( $M C$ and temperature) as a function of the surrounding climatic conditions (Fig. 1).

At this scale, we propose an extended van Meel model, able to account for the coupling between heat and mass transfer in an explicit way [13]:

$$
\begin{aligned}
j_{v, \text { wood }} \cdot A_{\text {wood }} & =-\dot{\bar{X}} \cdot m_{0} \\
& =k_{m} \cdot C \cdot M_{v} \cdot A_{\text {wood }} \cdot \ln \frac{P_{\text {atm }}-P_{v}^{\infty}}{P_{\text {atm }}-P_{v}^{\text {surf }}} \\
j_{h, \text { wood }} \cdot A_{\text {wood }} & =-m_{0} \cdot\left(c_{P, \text { wood }}+\bar{X} \cdot c_{P, l}\right) \cdot \dot{\bar{T}}+m_{0} \cdot \dot{\bar{X}} \cdot\left(L_{v}(\bar{T})+c_{P, l}\left(T^{\text {surf }}-\bar{T}\right)\right) \\
& =-h \cdot\left(T_{d b}^{\infty}-T^{\text {surf }}\right) \cdot A_{\text {wood }}
\end{aligned}
$$

In these equations, $m_{0}$ is the dry mass of the particle and $C$ is the molar concentration in the boundary layer. 
In equation (1), the vapor flux $j_{v \text {, wood }}$ at the exchange surface of the particle $A_{\text {wood }}$ is directly tied to the mass variations as a result of the mass balance over the entire particle. This flux is determined by the product of a mass transfer coefficient, the surface area of the particle and the driving force (film theory).

In equation (2), the heat flux $j_{h \text {, wood }}$ through the exchange surface of the particle $A_{\text {wood }}$ is directly tied to the sensible and latent heat variations of the moist wood due to the energy balance of the particle; the driving force is proportional to the difference of temperature between the air and the particle.

The vapor pressure at the surface of the particle is evaluated through the surface activity $a^{*}$ :

$P_{v}^{\text {surf }}=a^{*}(\phi, R H) \cdot P_{v s}\left(T^{\text {surf }}\right)$

Contrary to the water activity, which assumes a local thermodynamic equilibrium, the surface activity $a^{*}$ is a function allowing for the vapor pressure at the surface to be evaluated during drying through values averaged over the entire particle. Thus, the surface activity is no longer an equilibrium value but a kinetic parameter of the model.

During drying, the value of $a^{*}$ decreases from 1 , when free water exists at the surface, to $R H$, when the particle is in equilibrium with the surrounding air. Following the concept of characteristic drying curve, the surface activity is a function of $R H$ and $\phi$, the dimensionless $M C$ of wood:

$\phi=\left\{\begin{array}{c}1 \quad \text { if } \bar{X} \geq X_{c r} \\ \frac{\bar{X}-X_{e q}}{X_{c r}-X_{e q}} \quad \text { if } \bar{X}<X_{c r}\end{array}\right.$

The main assumption of this model is that the temperature of the studied particles is uniform inside the particle:

$$
T^{\text {surf }}=\bar{T}
$$

The assumption of temperature homogeneity is obviously relevant for small particles (small Biot number). It remains valid for large particle (characteristic dimension in the order of $10 \mathrm{~cm}$ ) because the characteristic time of heat transfer is much lower than the one of mass transfer. This was reported several times in the literature for convective drying, either for measurements or simulation results. Indeed, during convective drying, the particle temperature evolves slowly as consequence of the evolution of surface moisture content. Due to this slow variation, the temperature field has enough time to diffuse inside the product, giving rise to a quasi-uniform temperature.

Equations (1), (2) and (3) become: 


$$
\begin{aligned}
& -\dot{\bar{X}} \cdot m_{0}=k_{m} \cdot C \cdot M_{v} \cdot A_{\text {wood }} \cdot \ln \frac{P_{a t m}-P_{v}^{\infty}}{P_{a t m}-a *(\phi, R H) \cdot P_{v s}(\bar{T})} \\
& -h \cdot\left(T_{d b}^{\infty}-\bar{T}\right) \cdot A_{\text {wood }}=-m_{0} \cdot\left(c_{P, \text { wood }}+\bar{X} \cdot c_{P, l}\right) \cdot \dot{\bar{T}}+m_{0} \cdot \dot{\bar{X}} \cdot L_{v}(\bar{T})
\end{aligned}
$$

This extended van Meel model being a characteristic drying curve based analytical model, all the internal mechanisms - heat and mass transfer - are implicitly considered through the surface activity, $a^{*}$.

In order to faithfully simulate the evolution of the particle parameters, $a^{*}$ must be previously identified by inverse analysis of drying kinetics of single particles under different drying conditions (temperature and $R H$ ). These drying kinetics can be obtained by performing numerous experiments for any geometry or any wood species. However, this tedious task was reduced in our case by using the 3D version of TransPore [14], a computational model simulating heat and mass transfer in porous media, to generate drying kinetics under a wide range of climatic conditions and for any particle size. This is however limited to the species for which TransPore is currently validated (beech and spruce), and for quite simple geometries.

Equations (6) and (7) are discretized in time using a Taylor series formulation, truncated at the first order, via a fully explicit scheme. The state of the system and the flux are assumed constant between times $t$ and $t+\Delta t$.

\section{From the particle to the dryer: a multiscale approach}

The global model calculates the evolution of the air and wood parameters along the drying chamber using all fluxes exchanged between each particle. The system of equations describing the stack configuration [4] takes into account the two-way coupling between particles and dryer [13]:

$$
\begin{aligned}
& \frac{\partial q_{m, v}}{\partial x}=j_{v, \text { wood }} \cdot A_{\text {linspe.,wood }}+j_{v, \text { wall }} \cdot A_{\text {linspe.,wall }} \\
& \left(q_{m, a} \cdot c_{P, a}+q_{m, v} \cdot c_{P, v}\right) \cdot \frac{\partial T_{d b}^{\infty, \text { in }}}{\partial x}=A_{\text {lin.spe.,wood }} \cdot\left(j_{h, \text { wood }}+j_{v, \text { wood }} \cdot c_{P, v} \cdot\left(T_{\text {wood }}-T_{d b}^{\infty, \text { in }}\right)\right) \\
& +A_{\text {lin.spe, wall }} \cdot\left(j_{h, \text { wall }}+j_{v, \text { wall }} \cdot c_{P, v} \cdot\left(T_{\text {wall }}-T_{d b}^{\infty, \text { in }}\right)\right)
\end{aligned}
$$

$A_{\text {lin.spe. }}$ refers to a linear specific area - in square meter of exchange surface of wood/air or wall/air per linear meter of kiln along its main axis i.e. the direction of biomass displacement.

In this model, it is assumed that the climatic conditions are homogeneous in any cross-section of the dryer. 


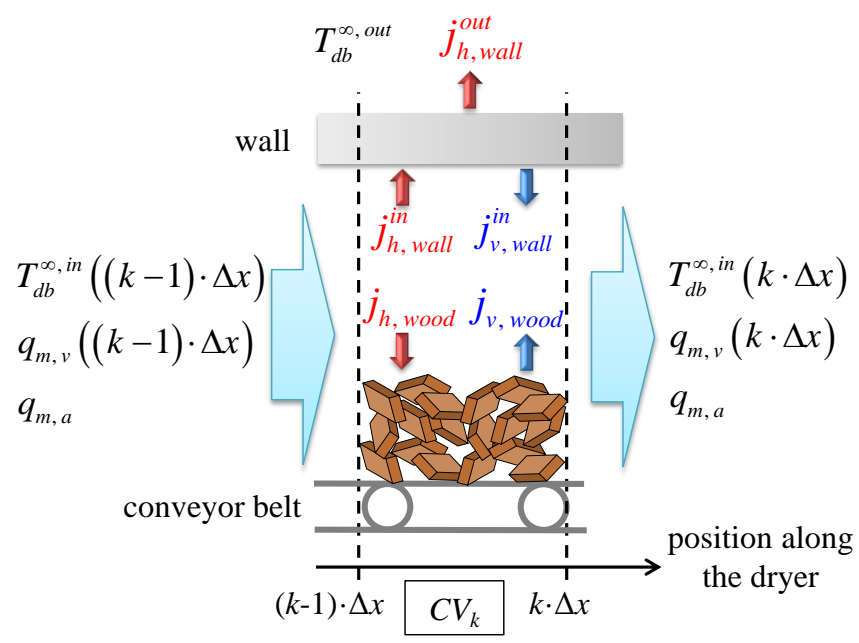

Fig. 2. Heat and mass fluxes inside a Control Volume for a conveyor dryer

Equations (8) and (9) are discretized in space using a Taylor series formulation, truncated at the first order, via a fully explicit scheme. The dryer is then segmented along its main axis into $N$ Control Volumes (CV), each containing $M$ particles (Fig. 2). For the $k^{\text {th }} \mathrm{CV}$, the state of the system and the flux are assumed constant between the positions $(k-1) \cdot \Delta x$ and $k \cdot \Delta x$.

The climatic conditions along the dryer are evaluated from the local heat and mass fluxes simulated for each particle. Thus, the global model is connected to thousands of local models (extended van Meel models), which emphasizes the need for a low computational time for the simulation of each particle behavior during the drying. In order to improve its predictive potential, the global model takes into account the heat losses as well as the possible condensation at the kiln wall.

The computational solution of the multiscale model is encoded in a custom software - DryKiln_CRP - written in Fortran 90.

Particular attention is paid to the structure of the model so that it is suitable for a wide range of continuous dryers: it can handle parallel- and counter-flow configurations, several air injection or exhaust points and air recirculation.

This new multiscale model is then validated by comparing simulations and experimental kinetics collected using an original device [13].

With the help of two - fictitious but relevant - case studies, the following sections aim at demonstrating the potential of DryKiln_CRP as an engineering tool. 


\section{Description of the studied case}

A company needs to produce one ton per hour (anhydrous mass flow-rate) of dry beech with an average $M C$ less than $20 \%$ and a heterogeneity of $M C$ lower than $10 \%$.

After harvesting, woody biomass is ground into large wood chips $(60 \times 40 \times 20 \mathrm{~mm})$. The macroporosity of the resulting granular medium is equal to 0.6. It is then stored in bulk to let it dry in open air for a few weeks, bringing its $M C$ down to an average of $60 \%$ with a standard deviation of $5 \%$. Finally the drying process is finished in an industrial plant (Fig. 3). The company has a fixed-bed dryer, $4 \mathrm{~m}$ high and $3 \mathrm{~m}$ in diameter. The wood goes through the vertical drying tower from top to bottom, and the air from bottom to top: this is a counterflow configuration. The dryer is supplied with warm air through a waste heat source from a nearby industrial facility. The inlet temperature of the air is $60{ }^{\circ} \mathrm{C}$, its $R H$ is $4.3 \%$, and its volume flow-rate is $5 \mathrm{~m}^{3} \cdot \mathrm{s}^{-1}$. The value of the heat transfer coefficient $\left(49 \mathrm{~W} \cdot \mathrm{m}^{-2} \cdot \mathrm{K}^{-1}\right)$ is calculated thanks to the formula proposed by Nganhou [15] and the value of the mass transfer coefficient $\left(0.046 \mathrm{~m} \cdot \mathrm{s}^{-1}\right)$ is obtained by transfer analogy [16, 17]. For these climatic conditions and this geometry of particles, the critical moisture content - identified from simulated kinetics (TransPore 3D) - is equal to $103 \%$.

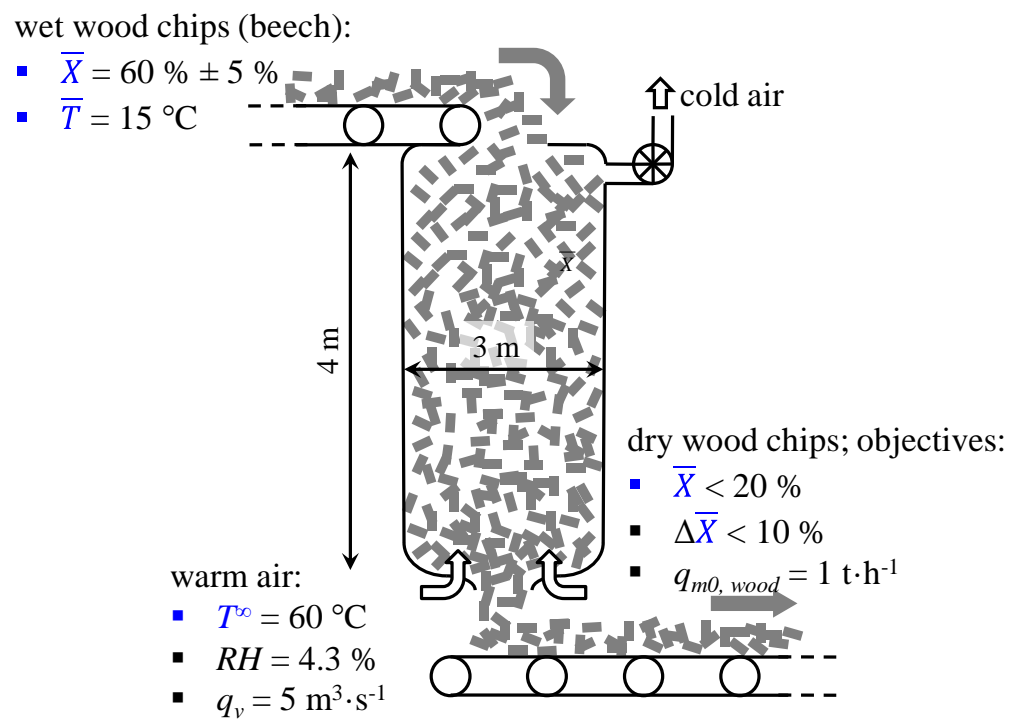

Fig. 3. Schematic description of the fixed bed dryer

The wall consists of a single steel sheet (Table 1).

Table 1. Characteristics of the drying tower wall

\begin{tabular}{|c|c|c|c|}
\hline $\begin{array}{c}\text { thickness } \\
(\mathbf{c m})\end{array}$ & $\begin{array}{c}\boldsymbol{\rho} \\
\left(\mathrm{kg}^{-\mathbf{3}} \mathbf{m}^{-\mathbf{3}}\right)\end{array}$ & $\begin{array}{c}\boldsymbol{c}_{\boldsymbol{P}} \\
\left(\mathbf{J} \cdot \mathbf{k g}^{-\mathbf{1}} \cdot \mathbf{K}^{-\mathbf{1}}\right)\end{array}$ & $\begin{array}{c}\boldsymbol{\lambda} \\
\left(\mathbf{W} \cdot \mathbf{m}^{-\mathbf{1}} \cdot \mathbf{K}^{-\mathbf{1}}\right)\end{array}$ \\
\hline 1 & 7500 & 450 & 45 \\
\hline
\end{tabular}


The climatic conditions outside of the dryer are as follows: air temperature $=15^{\circ} \mathrm{C}, R H=50 \%$ and heat transfer coefficient $=8 \mathrm{~W} \cdot \mathrm{m}^{-2} \cdot \mathrm{K}^{-1}$

The initial drying process does not therefore meet the specifications required. The multiscale model is then used test different ways which may be employed to overcome this problem, and finally to propose adequate technical solutions.

\section{The initial configuration}

The flow-rate is set to meet the company needs: one ton of dry mass per hour.

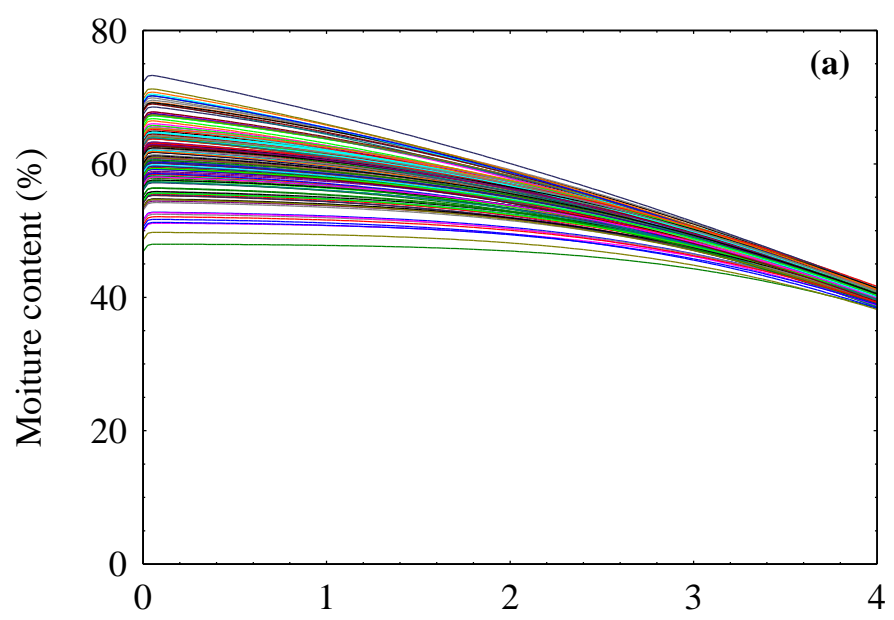

Distance from the top of the dryer $(\mathrm{m})$

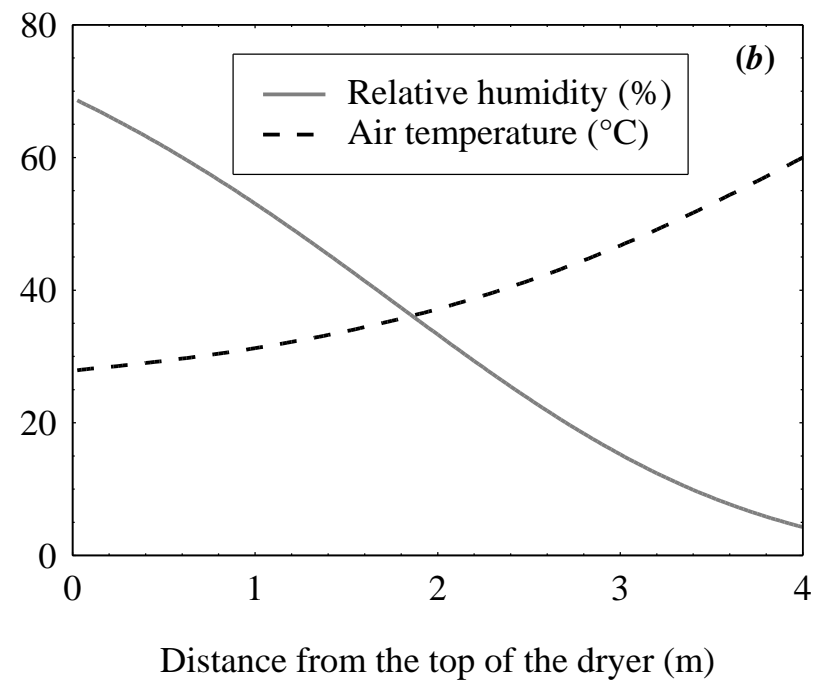

Fig. 4. Simulated evolution of the wood particles $M C(\boldsymbol{a})$ and of the climatic conditions $(\boldsymbol{b})$ along the dryer for the initial configuration 
This configuration does not achieve the qualitative requirements for the downstream processes: at the dryer outlet the average $M C$ of wood chips is $40.4 \%$ (Fig. 4). It is therefore necessary to identify technical solutions to optimize this configuration.

Decrease of the wood flow-rate

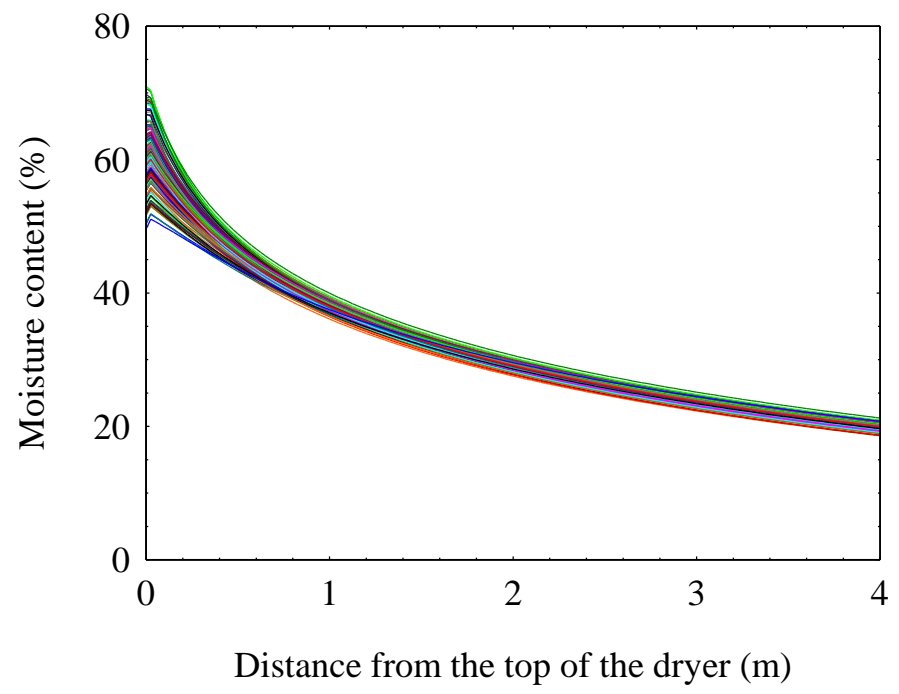

Fig. 5. Simulated evolution of the wood particles $M C$ for a bed speed set to $0.20 \mathrm{~m} \cdot \mathrm{h}^{-1}\left(311 \mathrm{~kg} \cdot \mathrm{h}^{-1}\right)$

With a wood flow-rate equal to $311 \mathrm{~kg} \cdot \mathrm{h}^{-1}$, the average $M C$ of the biomass reaches $20 \%$ at the outlet of the dryer, and the dispersion of these values is about $2.7 \%$ (Fig. 5). This configuration achieves the qualitative objectives. However, from a quantitative point of view, the mass flow-rate of dry wood is only one-third of the requirement.

\section{Thermal insulation of the dryer wall}

Now we thermally insulate the drying tower by covering its outer face with a $110 \mathrm{~mm}$ thick layer made of glass wool in order to decrease heat loss through the wall (Table 2). The saved energy is expected to improve the plant performance.

Table 2. Characteristics of the insulated drying tower wall

\begin{tabular}{|c|c|c|c|c|}
\hline & $\begin{array}{c}\text { thickness } \\
(\mathbf{c m})\end{array}$ & $\begin{array}{c}\boldsymbol{\rho} \\
\left(\mathbf{k g} \cdot \mathbf{m}^{-\mathbf{3}}\right)\end{array}$ & $\begin{array}{c}\boldsymbol{c}_{\boldsymbol{P}} \\
\left(\mathbf{J} \cdot \mathbf{k g}^{-\mathbf{1}} \cdot \mathbf{K}^{-\mathbf{1}}\right)\end{array}$ & $\begin{array}{c}\lambda \\
\left(\mathbf{W} \cdot \mathbf{m}^{-\mathbf{1}} \cdot \mathbf{K}^{-\mathbf{1}}\right)\end{array}$ \\
\hline steel & 1 & 7500 & 450 & 45 \\
\hline glass wool & 11 & 1039 & 35 & 0.039 \\
\hline \multirow{2}{*}{ equivalent } & 12 & \multicolumn{2}{|c|}{$\begin{array}{c}\boldsymbol{\rho}^{-c_{\boldsymbol{P}}} \\
\left(\mathbf{J} \cdot \mathbf{m}^{-3} \cdot \mathbf{K}^{-1}\right)\end{array}$} & 0.043 \\
\cline { 2 - 4 } & & \multicolumn{2}{|c|}{$3.15 \cdot 10^{5}$} & \\
\hline
\end{tabular}




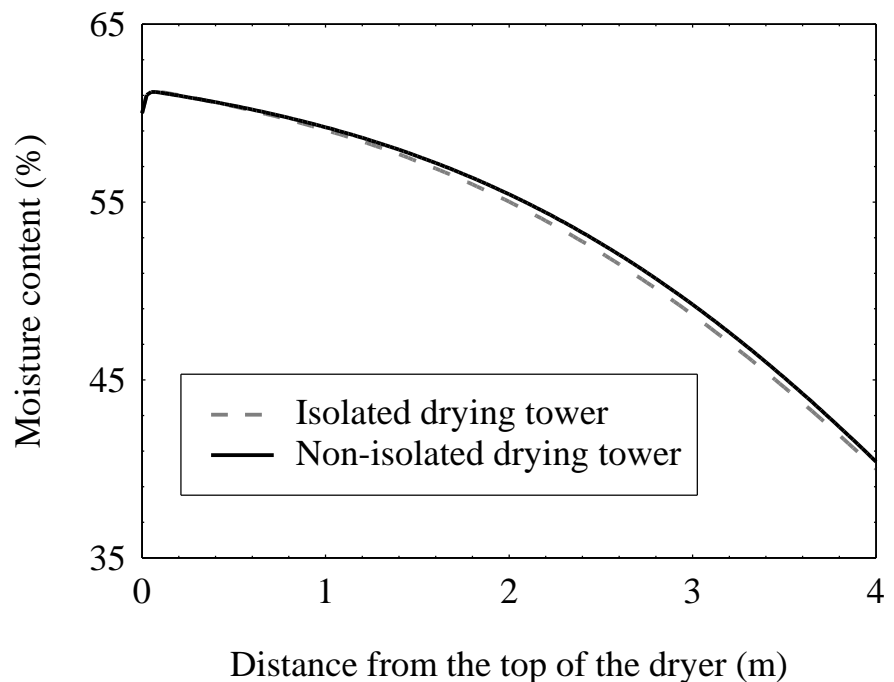

Fig. 6. Simulation of the drying quality improvement thanks to the thermal insulation of the wall

Table 3. Influence of the wall insulation on the energy performance of the dryer

\begin{tabular}{|c|c|c|c|c|c|}
\hline \multirow{2}{*}{$\begin{array}{l}\text { insulated } \\
\text { wall }\end{array}$} & \multirow{2}{*}{$\begin{array}{c}\text { outlet } \\
M C \\
(\%)\end{array}$} & \multicolumn{2}{|c|}{$\begin{array}{c}\text { exhausted } \\
\text { air }\end{array}$} & \multirow{2}{*}{$\begin{array}{c}\text { yield } \\
(\%)\end{array}$} & \multirow{2}{*}{$\begin{array}{c}\text { heat } \\
\text { loss } \\
(\%)\end{array}$} \\
\hline & & $\begin{array}{c}T^{\infty} \\
\left({ }^{\circ} \mathbf{C}\right)\end{array}$ & $\begin{array}{l}R H \\
(\%)\end{array}$ & & \\
\hline without & 40.4 & 27.0 & 69.6 & 55.8 & 2.66 \\
\hline with & 40.0 & 27.6 & 68.0 & 56.9 & 0.17 \\
\hline
\end{tabular}

The energy yield is defined as the share of the heat source power used for evaporating the water from the wood.

DryKiln_CRP is a useful tool to test the performance of the wall insulation. With a wood flow-rate equal to one ton per hour, the gain is perceptible but remains low (Fig. 6). Regarding the outlet $M C$ of the wood, the difference between the initial configuration and the current one is lower than $0.5 \%$ (Table 3 ). With the insulated dryer, we need to decrease the wood flow-rate to $325 \mathrm{~kg} \cdot \mathrm{h}^{-1}$ to reach an average $M C$ of $20 \%$. The increase of productivity obtained thanks to the thermal insulation of the wall is not negligible $\left(14 \mathrm{~kg} \cdot \mathrm{h}^{-1}\right)$. Because of its low cost and its long-term benefit, thermal insulation of the wall is implemented. This however is clearly far not enough to meet the company requirements, and it must be coupled with other technical solutions.

\section{Reduction of the particle size}

The analysis of Fig. 4-b tells us that the air is not fully saturated with moisture at the outlet of the dryer. Thus the evaporation capacity of the fluid is not totally exploited. The resistance to internal transfer within large wood chips certainly limits the drying rate. In order to test this hypothesis, we examine the drying of smaller wood chips: $20 \times 20 \times 5 \mathrm{~mm}$. This reduction of the particle size affects the surface activity and the critical moisture content rises up to $107 \%$. 


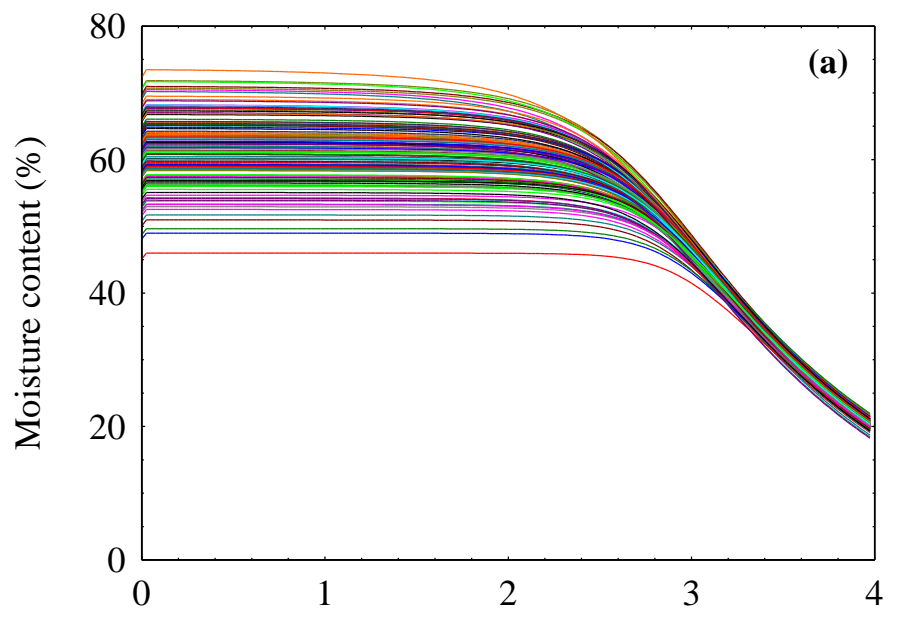

Distance from the top of the dryer $(\mathrm{m})$

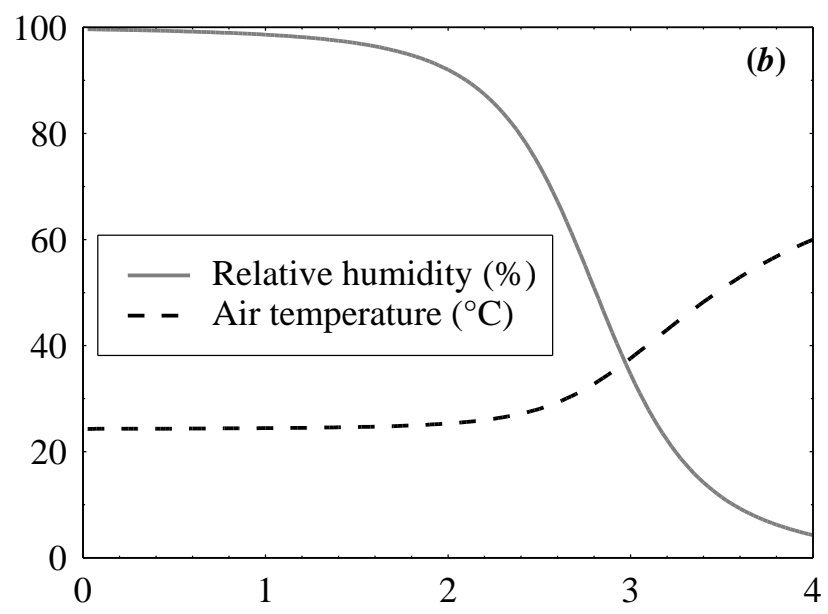

Distance from the top of the dryer $(\mathrm{m})$

Fig. 7. Simulated evolution of the $M C$ of small wood chips $(\boldsymbol{a})$ and of the climatic conditions $(\boldsymbol{b})$ along the dryer for a bed speed equal to $0.41 \mathrm{~m} \cdot \mathrm{h}^{-1}\left(639 \mathrm{~kg} \cdot \mathrm{h}^{-1}\right)$

The quality requirements limit the flow-rate of small wood chips to $639 \mathrm{~kg} \cdot \mathrm{h}^{-1}$ (Fig. 7 -a). Of course this is lower than the target flow-rate $\left(1 \mathrm{t} \cdot \mathrm{h}^{-1}\right)$ but is almost twice as high as the maximum flux previously identified for the large particles $\left(325 \mathrm{~kg} \cdot \mathrm{h}^{-1}\right)$. We can notice that the MC decreases very slowly for the two first meters of the dryer. The air is indeed almost saturated in this part of the dryer (Fig. 7-b), and the tower could be smaller in height without affecting the quality of drying.

Table 4. Summary of qualitative, quantitative and energy aspects of the studied configurations

\begin{tabular}{|c|c|c|c|c|c|}
\hline \multirow[b]{2}{*}{$\begin{array}{l}\text { wood } \\
\text { chips }\end{array}$} & \multirow{2}{*}{$\begin{array}{c}\text { flow-rate } \\
\left(\mathbf{k g} \cdot \mathbf{h}^{-1}\right)\end{array}$} & \multirow{2}{*}{$\begin{array}{c}\text { outlet } M C \\
(\%)\end{array}$} & \multicolumn{2}{|c|}{ outlet air } & \multirow{2}{*}{$\begin{array}{c}\text { yield } \\
(\%)\end{array}$} \\
\hline & & & $\begin{array}{c}T^{\infty} \\
\left({ }^{\circ} \mathrm{C}\right) \\
\end{array}$ & $\begin{array}{l}R H \\
(\%)\end{array}$ & \\
\hline \multirow[t]{2}{*}{ large } & 1000 & 40.0 & 27.6 & 68.0 & 56.9 \\
\hline & 325 & 20.0 & 41.4 & 24.4 & 37.4 \\
\hline \multirow[t]{2}{*}{ small } & 1000 & 36.1 & 23.2 & 100.0 & 67.9 \\
\hline & 639 & 20.0 & 24.0 & 99.9 & 72.7 \\
\hline
\end{tabular}


With the initial size of wood chips, the drying rate was indeed controlled by the resistance to internal transfer. It is then not possible to exploit the full evaporation potential of the air (Table 4). In the case of the configuration with a wood mass flow-rate optimized for large particles $\left(325 \mathrm{~kg} \cdot \mathrm{h}^{-1}\right)$, the air at the outlet remains warm $\left(41.4{ }^{\circ} \mathrm{C}\right)$ and far from saturation $(24.4 \%)$. Thus it is not surprising that this open system (no air recirculation device) has a very low energy yield $(37.4 \%)$. The reduction of the wood chips size is therefore a simple and efficient solution to optimize the drying performance. However, before implementing this solution, the company must ensure that this particle size is compatible with the downstream processes. Furthermore, the additional cost of grinding should be evaluated ex ante.

\section{Additional heat source}

Whatever the particle size, an additional heat source is needed to reach the target wood flow-rate $\left(1 \mathrm{t} \cdot \mathrm{h}^{-1}\right)$ through increasing the evaporation potential of air. DryKiln_CRP is then useful to define the required power. Two parameters of the heat source can be adjusted: flow-rate and temperature.

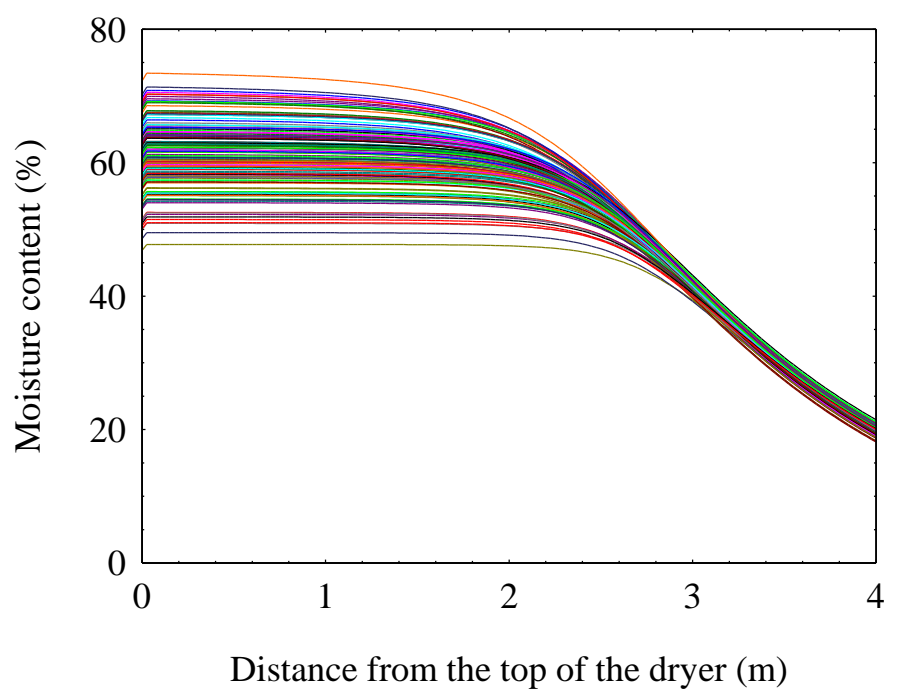

Fig. 8. Simulated evolution of the $M C$ of small wood chips along the dryer supplied with an additional heat source $(136 \mathrm{~kW})$

For the drying of small wood chips $(20 \times 20 \times 5 \mathrm{~mm})$, we increase the air flow-rate at the same temperature $\left(60{ }^{\circ} \mathrm{C}\right)$. This flow-rate must reach $7.8 \mathrm{~m}^{3} \cdot \mathrm{s}^{-1}-$ to be compared to the initial value of $5 \mathrm{~m}^{3} \cdot \mathrm{s}^{-1}-$ in order to meet all the specifications. The corresponding additional power required is $136 \mathrm{~kW}$ (Fig. 8). 


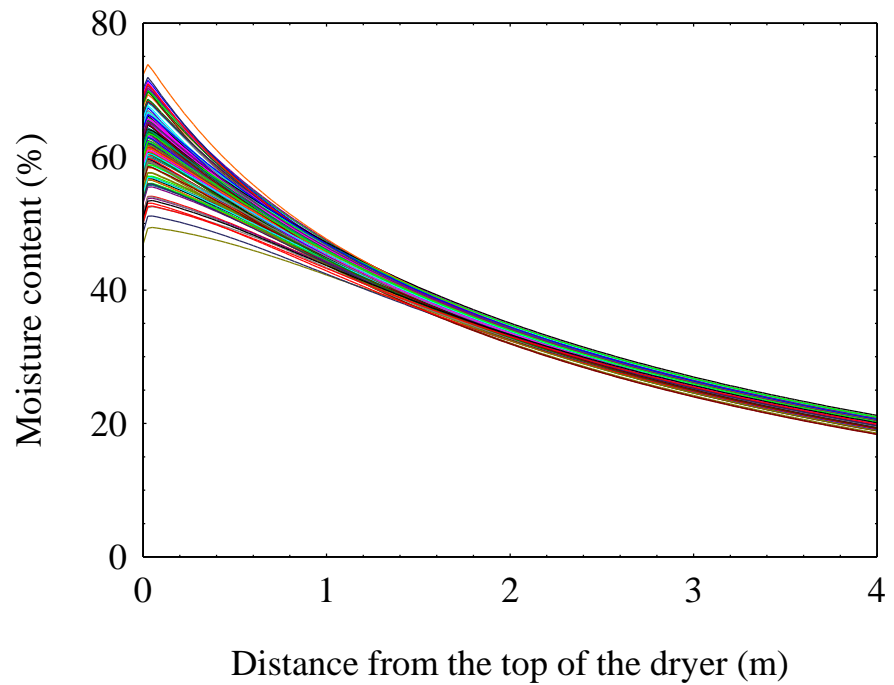

Fig. 9. Simulated evolution of the $M C$ of large wood chips along the dryer supplied with an additional heat source $(318 \mathrm{~kW})$

If the downstream processes are not compatible with a fine grinding, an increase in the air temperature has two positive effects; a better evaporation potential and a thermal activation of internal transfer which is very useful for the drying of large particles $(60 \times 40 \times 20 \mathrm{~mm})$. With an air flow-rate equal to $7.8 \mathrm{~m}^{3} \cdot \mathrm{s}^{-1}$, the temperature should reach $87^{\circ} \mathrm{C}$ to ensure the quality of the dry wood. The additional heating power is then $318 \mathrm{~kW}$ (Fig. 9).

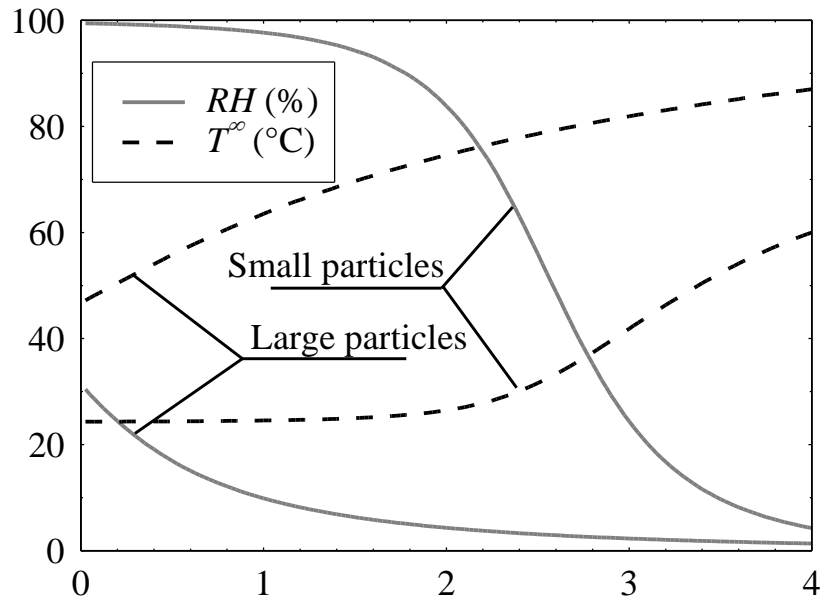

Distance from the top of the dryer $(\mathrm{m})$

Fig. 10. Simulated evolution of the climatic conditions along the dryer supplied with additional heat sources

Compared to the drying of small particles, the temperature of the outlet air is higher in this case - at respectively $24.0{ }^{\circ} \mathrm{C}$ and $45.3{ }^{\circ} \mathrm{C}$ - and its relative humidity is farther from saturation - at respectively $99.4 \%$ and $32.2 \%$ (Fig. 10). Thus the energy yield of small particles is higher than in the case of large particles - at respectively $72.5 \%$ and $49.9 \%$. The results of simulation allow us also to estimate the energy efficiency, i.e. the specific energy supplied by ton of evaporated water by differentiating the waste and the additional heat sources (Table 5). 
Table 5. Energy efficiency of the drying with additional heat sources

\begin{tabular}{|l|c|c|c|}
\hline $\begin{array}{c}\text { wood } \\
\text { chips }\end{array}$ & $\begin{array}{c}\text { global energy } \\
\text { efficiency }(\mathbf{k W h} / \mathbf{k g})\end{array}$ & $\begin{array}{c}\text { from waste heat } \\
\text { source }(\mathbf{k W h} / \mathbf{k g})\end{array}$ & $\begin{array}{c}\text { from additional heat } \\
\text { source }(\mathbf{k W h} / \mathbf{k g})\end{array}$ \\
\hline small & 0.95 & 0.61 & 0.34 \\
\hline large & 1.41 & 0.80 & 0.61 \\
\hline
\end{tabular}

In both case, the configurations achieve the qualitative requirements for heterogeneity of $M C$ : the dispersion of values is respectively about $3.3 \%$ and $2.8 \%$.

On the one hand, Fig. 8 and Fig. 10 confirm that internal transfers are intensified by the grinding of the wood into small particles. In this case, because of the moisture-saturated air, the two first meters from the top of the dryer are useless. The wood flow-rate is driven by evaporation potential of air. On the other hand, the drying performance of large particles remains limited by internal transfers (Fig. 9 and Fig. 10 ). The wood flow-rate is now driven by the drying kinetic of the single particle. There is therefore an intermediate particle size that enables to exploit the full evaporation potential of the air while using the entire height of the dryer. The drying performance is then comparable to the value obtained for small particles, but the energy required for the grinding of the wood is lower. Thus, the particle size is a key parameter for the energy and economic optimization of the whole production line.

Whether by determining the power of the additional heat source needed, or by calculating the energy performance of each configuration, DryKiln_CRP is a powerful tool for the improvement of existing dryers.

\section{DESIGN OF A CONVEYOR DRYER}

\section{Description of the studied case}

A company needs to produce $450 \mathrm{~kg} \cdot \mathrm{h}^{-1}$ (anhydrous flow-rate) of dry wood for the production of charcoal. Before carbonization, the mean and the heterogeneity of the wood MC must be lower than respectively $15 \%$ and $10 \%$. The woody biomass is composed of eucalyptus logs (assumed to be cylindrical, Table 6):

Table 6. Characteristics of eucalyptus logs to dry

\begin{tabular}{|c|c|c|}
\hline parameter & mean & standard deviation \\
\hline length $(\mathrm{mm})$ & 300 & 20 \\
\hline diameter $(\mathrm{mm})$ & 85 & 5 \\
\hline density $\left(\mathrm{kg} \cdot \mathrm{m}^{-3}\right)$ & 600 & $/$ \\
\hline initial $M C(\%)$ & 90 & 10 \\
\hline temperature $\left({ }^{\circ} \mathrm{C}\right)$ & 20 & $/$ \\
\hline bed macroporosity & $2 / 3$ & $/$ \\
\hline
\end{tabular}

The company wants to build an industrial continuous dryer to pretreat this wet raw material. In order to reduce the operating costs, the dryer will be supplied with warm air through a waste heat source from a nearby industrial facility: the inlet temperature of the air is $120^{\circ} \mathrm{C}$, its $R H$ is $0.59 \%$, and its volume flow-rate is $4.5 \mathrm{~m}^{3} \cdot \mathrm{s}^{-1}$. The 
use of a conveyor dryer is appropriate due to the large particle size. The conveyor belt carries a $50 \mathrm{~cm}$ thick bed of $\log s$ - which is thin compared to the particle size - through a tunnel. The cross-section inside this tunnel is $1 \mathrm{~m}$ high and $3 \mathrm{~m}$ wide. Considering this bed configuration and the heat source characteristics, the values of the heat and mass transfer coefficients are respectively equal to $29 \mathrm{~W} \cdot \mathrm{m}^{-2} \cdot \mathrm{K}^{-1}$ and $0.032 \mathrm{~m} \cdot \mathrm{s}^{-1}[15-17]$. For these climatic conditions and this geometry of particles, the critical moisture content - identified from experimental kinetics - equals to $78.0 \%$. The wall consists of a $200 \mathrm{~mm}$ thick inner layer of concrete and a $100 \mathrm{~mm}$ thick outer layer of glass wool.

By using the multiscale model, the best airflow configuration will be identified. The objective is to meet the specifications while designing a dryer as short as possible in order to reduce the investment costs.

\section{Simple airflow configurations}
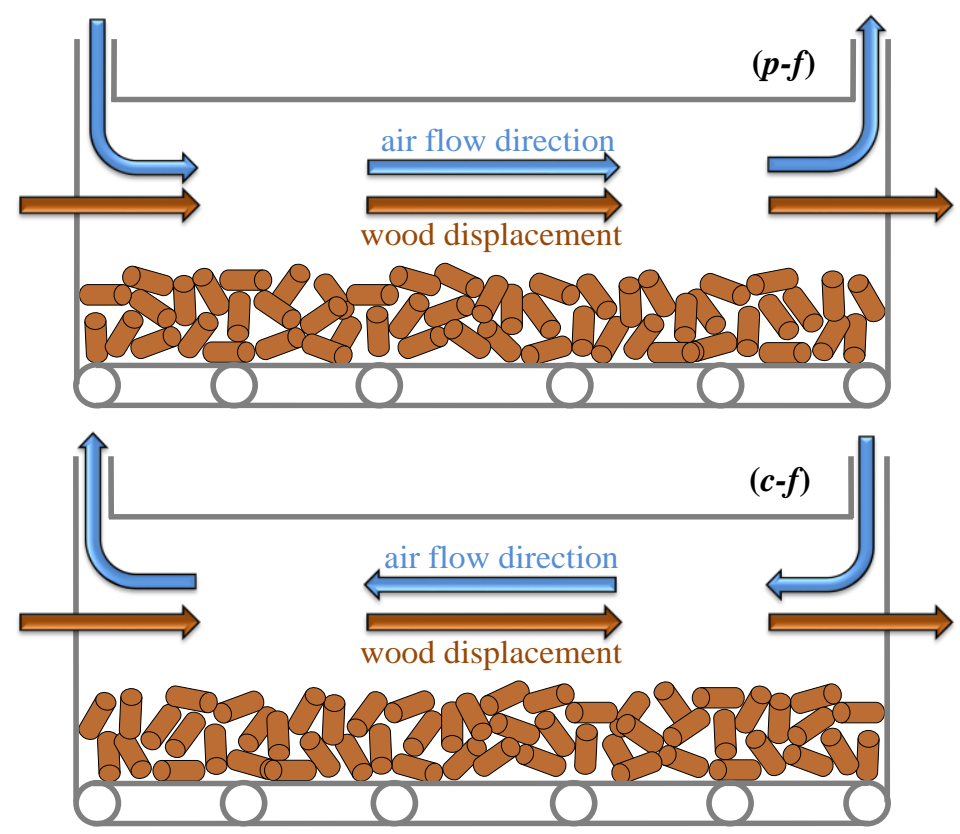

Fig. 11. Simple airflow configurations: parallel-flow, $(\boldsymbol{p}-\boldsymbol{f})$ and counter-flow $(\boldsymbol{c}-\boldsymbol{f})$

In the case of simple configurations, the tunnel has a single point of air injection and a single point of air exhaust (Fig. 11). 
Table 7. Qualitative analysis of climatic conditions along the tunnel

\begin{tabular}{|c|c|c|c|}
\hline $\begin{array}{c}\text { position } \\
\text { along the } \\
\text { tunnel }\end{array}$ & parameter & $\begin{array}{c}\boldsymbol{p}-\boldsymbol{f} \\
\text { config. }\end{array}$ & $\begin{array}{c}\boldsymbol{c}-\boldsymbol{f} \\
\text { config. }\end{array}$ \\
\hline \multirow{4}{*}{ beginning } & air temperature & high & low \\
\cline { 2 - 4 } & RH & low & high \\
\cline { 2 - 4 } & wood temperature & low & low \\
\cline { 2 - 4 } & $\begin{array}{c}\text { condensation at } \\
\text { the surface of the } \\
\text { particles }\end{array}$ & no & yes \\
\hline \multirow{4}{*}{ end } & air temperature & low & high \\
\cline { 2 - 4 } & RH & high & low \\
\cline { 2 - 4 } & wood temperature & low & high \\
\cline { 2 - 4 } & equilibrium $M C$ & high & low \\
\hline \multicolumn{2}{|c|}{ length of the tunnel (m) } & 20.75 & $\mathbf{1 0}$ \\
\hline
\end{tabular}

The $c-f$ configuration is the most efficient (Table 7): the tunnel is $10 \mathrm{~m}$ long, i.e. less than half the length for the case of the $p$ - $f$ configuration $(20.75 \mathrm{~m})$.

\section{Combined airflow configurations}
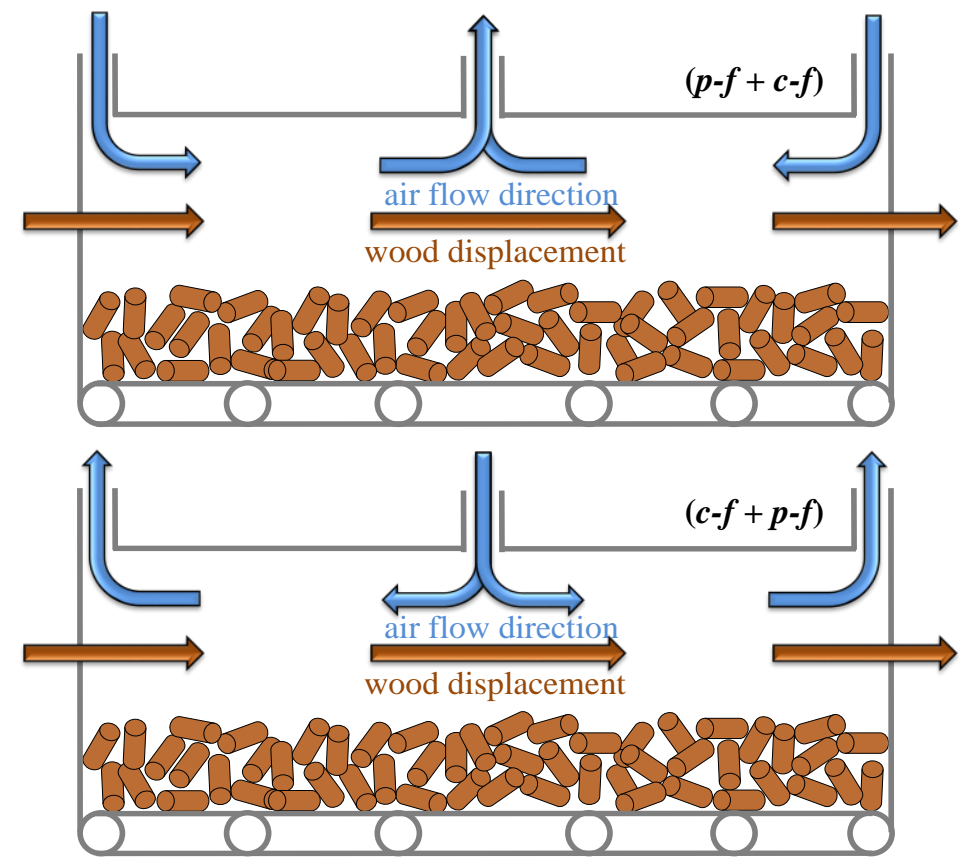

Fig. 12. Combined airflow configurations: parallel-flow followed by counter-flow $(\boldsymbol{p}-\boldsymbol{f}+\boldsymbol{c}-\boldsymbol{f})$ and counter-flow followed by parallel-flow $(\boldsymbol{c}-\boldsymbol{f}+\boldsymbol{p}-\boldsymbol{f})$

In light of the previous results, it seems possible to reduce the length of the dryer if we succeed in obtaining a high rate of drying at both the beginning and the end of the tunnel. To this end, air is injected at each end of the dryer with equal flow-rates, and the gas exhaust is located at the mid-length of the tunnel. This constitutes a $p-f+c-f$ configuration. The opposite configuration $(c-f+p-f)$ is also studied (Fig. 12). 


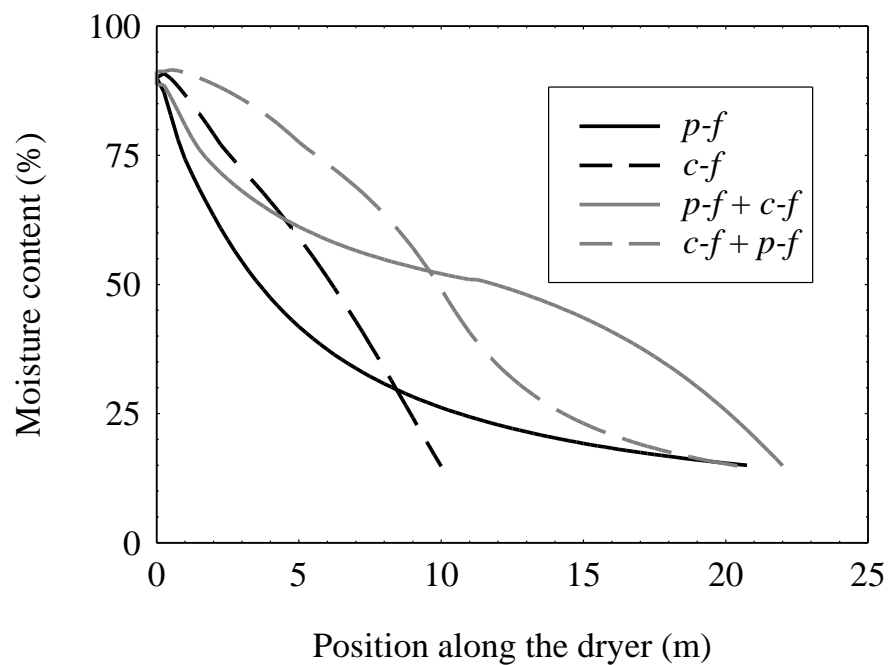

Fig. 13. Simulated evolution of the average $M C$ of the bed along the tunnel for simple and combined configurations

Fig. 13 shows that the expected gain is not obtained. The combined configurations do not significantly reduce the length of the dryer compared to the optimal length determined for each simple configuration. Moreover the $p-f+c-f$ configuration is less efficient than the $c-f+p-f$. These results are against the intuition that led to the study of the combined configurations; they confirm the usefulness of the model for validating or invalidating preconceived ideas and at a negligible cost compared with the building of a pilot plan.

DryKiln_CRP is also useful for studying the impact of an unequal distribution of the air flow-rate within the $c-f$ and $p$ - $f$ sections, or the effect of the displacement of the limit between these sections along the dryer. In both cases, the results are similar to the previous observation: sharing the heat source does not appear to be a promising solution, and the $c-f$ configuration remains the most efficient.

\section{Air recirculation system}

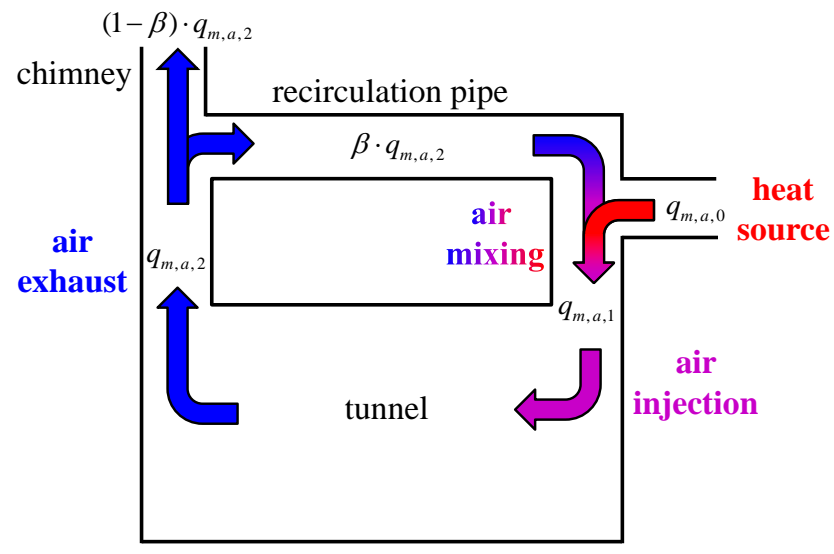

Fig. 14. Schematic diagram of the air recirculation system 
A recirculation system can be implemented in order to exploit the full evaporation potential of the air (Fig. 14).

The air flow-rate inside the tunnel increases with the recirculation rate $\beta$ whose value can vary between 0 and 1 .

The heat source parameters are unchanged. Moreover, we assume that there is neither heat loss through the recirculation pipe nor heat gain because of the recycling fan. The heat and mass balances at the mixing point allow us to calculate the injected air parameters from the heat source and exhausted air parameters, and the recirculation rate:

$$
\begin{aligned}
& q_{m, a, 1}=q_{m, a, 2}=\frac{1}{1-\beta} \cdot q_{m, a, 0} \\
& q_{m, v, 1}=q_{m, v, 0}+\beta \cdot q_{m, v, 2} \\
& T_{1}=\frac{c_{P, a} \cdot q_{m, a, 0} \cdot\left(\frac{\beta}{1-\beta} \cdot T_{2}+T_{0}\right)+c_{P, v} \cdot\left(q_{m, v, 0} \cdot T_{0}+\beta \cdot q_{m, v, 2} \cdot T_{2}\right)}{c_{P, a} \cdot \frac{1}{1-\beta} \cdot q_{m, a, 0}+c_{P, v} \cdot\left(q_{m, v, 0}+\beta \cdot q_{m, v, 2}\right)}
\end{aligned}
$$
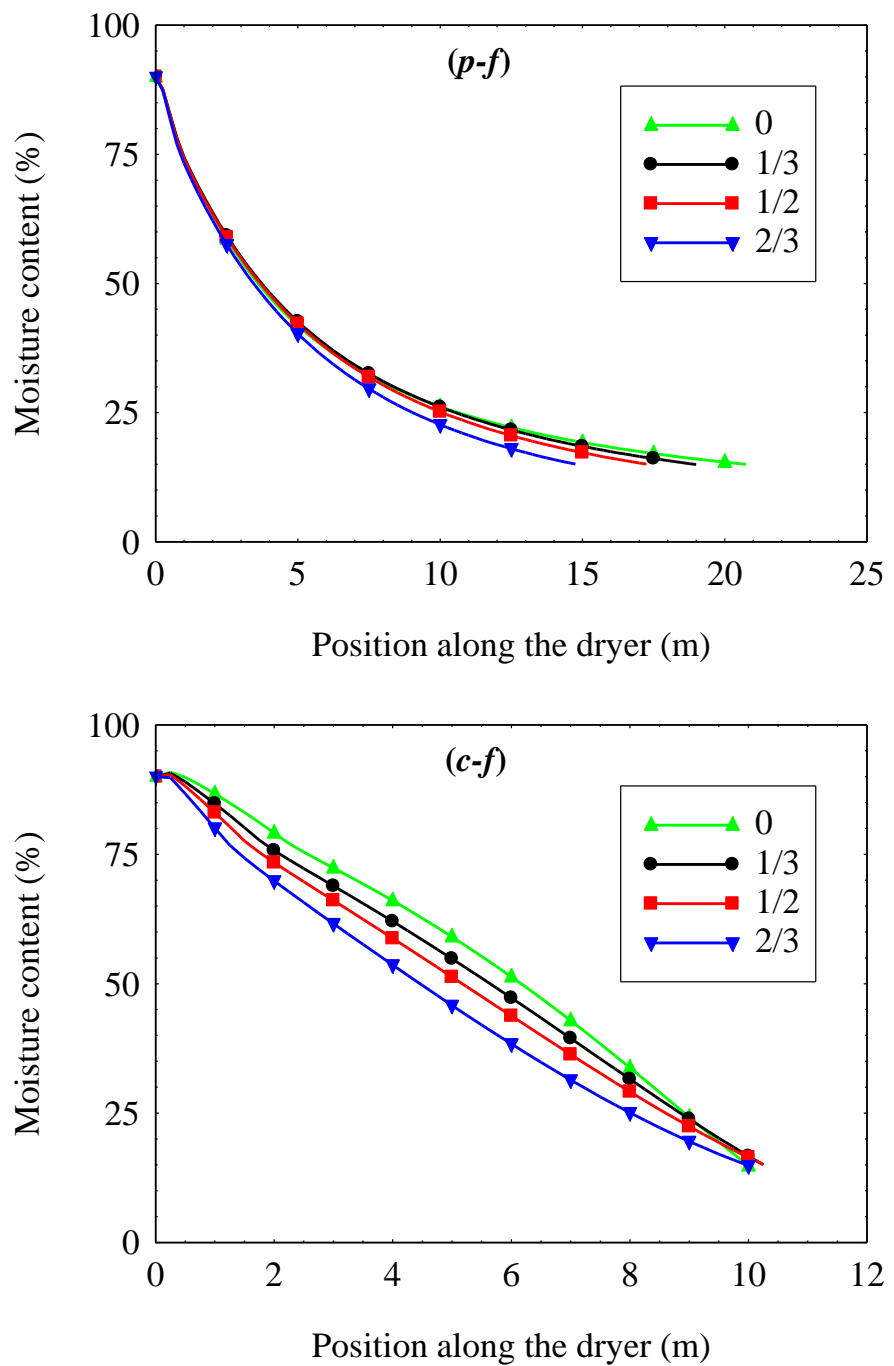

Fig. 15. Influence of the air recirculation rate on the length of the tunnel with $\boldsymbol{p}-\boldsymbol{f}$ and $\boldsymbol{c}-\boldsymbol{f}$ configurations

Unlike the $c-f$ configuration, the air recirculation has a positive effect on the $p-f$ configuration (Fig. 15). The increase in recirculation rate significantly reduces the tunnel length. However the tunnel remains longer 
$(14.25 \mathrm{~m})$ than the one with a $c-f$ configuration $(10 \mathrm{~m})$. Although the air recirculation cannot be used to make the tunnel shorter, it reduces the risk of fire because the temperature of the air injected into the tunnel decreases as the recirculation rate increases (from $120{ }^{\circ} \mathrm{C}$ when $\beta=0$ to $78.9^{\circ} \mathrm{C}$ when $\beta=2 / 3$ ).

\section{Optimization of the MC heterogeneity}

The $c$-f configuration meets the objective in terms of average $M C(15 \%)$ but the heterogeneity remains too high (14\%, Fig. 16). In order to obtain a $M C$ heterogeneity lower than $10 \%$, we must extend the tunnel by $4.5 \mathrm{~m}$, giving a total length of $14.5 \mathrm{~m}$. The average $M C$ of wood is then $5.3 \%$. An air recirculation rate equal to $2 / 3^{\text {rds }}$ allows the size of the dryer with a $p-f$ configuration to be limited to $14.75 \mathrm{~m}$ (Fig. 15). In this case, the $M C$ heterogeneity is about $9 \%$. Both dryers are similar regarding their length but the $c-f$ configuration $-14.5 \mathrm{~m}$ long

- does not need an air recirculation system. Thus the $c$ - $f$ configuration appears as the most suitable design because of its lower investment and operating costs.

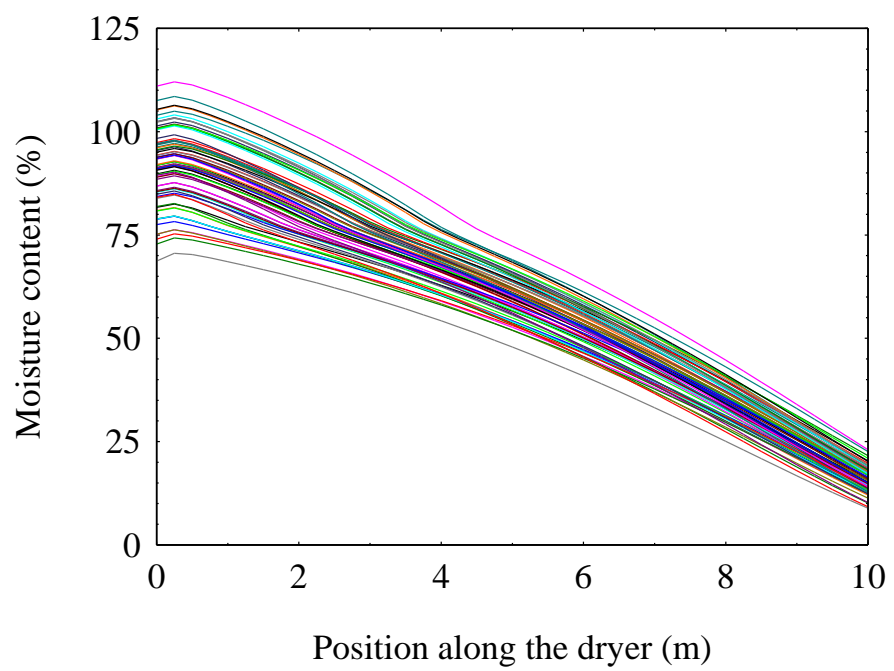

Fig. 16. Unsatisfying decrease of the $M C$ heterogeneity with the $c-f$ configuration

Through this example, DryKiln_CRP appears to be helpful to design new dryers, to test the relevance of technical solutions and finally to adjust the business plan.

\section{CONCLUSION}

The model DryKiln_CRP presented in this paper, based on an extended van Meel model at the particle level, is able to faithfully simulate the continuous drying of wood for energy purposes. As main feature, the multiscale structure of the model allows the coupling between the different spatial scales to be accounted for with a large number of particles (up to several thousands) with different properties. Thus, it is able to account for average fields, standard deviations and local values. Beyond its application to wood, this model - with its multiscale 
structure - can be applied to any other macroscopic granular medium that presents variability and for which the concept of characteristic drying curves is applicable. Finally, at the drier scale, the calculations of energy efficiency take into account the heat flows through the wall as well as any possible condensation that may occur at its surface.

Both case studies have demonstrated the potential of DryKiln_CRP as an engineering tool to design or optimize industrial facilities. Indeed, after having identified the surface activity of the product to dry - from drying kinetics obtained by labscale experiments or TransPore 3D simulations -, DryKiln_CRP is suitable for a wide range of configurations thanks to its ability to simulate parallel- and counter-flow configurations, several air injection or exhaust points, air recirculation and the wall thermal insulation of the wall. Such a tool allows us to reduce the investment and operating costs while saving energy while improving the quality of drying.

\section{NOMENCLATURE}

$a^{*}$

A

Alin.spe.

C

$c_{p}$

$h$

$j_{h}$

$j_{v}$

$k_{m}$

$L_{v}$

M

$m_{0}$

$P$

$q_{m}$

$q_{v}$ surface activity

surface area

$\mathrm{m}^{2}$

linear specific surface area

$\mathrm{m}^{2} \cdot \mathrm{m}^{-1}$

molar concentration of air

$\mathrm{mol} \cdot \mathrm{m}^{-3}$

heat capacity

$\mathrm{J} \cdot \mathrm{kg}^{-1} \cdot \mathrm{K}^{-1}$

heat transfer coefficient

$\mathrm{W} \cdot \mathrm{m}^{-2} \cdot \mathrm{K}^{-1}$

heat flux

$\mathrm{W} \cdot \mathrm{m}^{-2}$

mass flux

$\mathrm{kg} \cdot \mathrm{s}^{-1} \cdot \mathrm{m}^{-2}$

mass transfer coefficient

$\mathrm{m} \cdot \mathrm{s}^{-1}$

latent heat of vaporization

$\mathrm{J} \mathrm{kg}^{-1}$

molar mass

$\mathrm{kg} \cdot \mathrm{mol}^{-1}$

anhydrous mass of the particle

kg

pressure

$\mathrm{Pa}$

mass flow-rate

$\mathrm{kg} \cdot \mathrm{s}^{-1}$

volume flow-rate $\mathrm{m}^{3} \cdot \mathrm{s}^{-1}$ 
relative humidity

moisture content

Greek letters

$\beta$

$\phi$

Subscripts and superscripts

atm

$c r$

$d b$

$e q$

in

$l$

out

surf

$v$

vs

$\infty$ recirculation rate

dimensionless moisture content atmospheric

critical

dry bulb

equilibrium

inside the dryer

liquid water

outside the dryer

surface exchange

water vapor

saturation vapor

air-flow

\section{REFERENCES}

1. European Commission Innovating for sustainable growth: A bioeconomy for Europe. Communication to the European Parliament, the Council, the European Economic and Social Committee and the Committee of the Regions Brussels: Brussels, Belgium, February 13, 2012.

2. Damartzis, T.; Zabaniotou, A. Thermochemical conversion of biomass to second generation biofuels through integrated process design - A review. Renewable and Sustainable Energy Reviews 2011, 15 (1), 366-378. 
3. Perré, P. Multiscale aspects of heat and mass transfer during drying. Transport in Porous Media 2007, 66 (1-2), 59-76.

4. $\quad$ Perré, P.; Rémond, R. A Dual scale computational model of kiln wood drying including single board and stack level simulation. Drying Technology 2006, 4 (1-6), 1069-1074.

5. Patankar, S.V. Numerical heat transfer and fluid flow; Hemisphere Series on Computational Methods in Mechanics and Thermal Science, 1980.

6. Perré, P.; Degiovanni, A. Simulation par volumes finis des transferts couplés en milieux poreux anisotropes: séchage du bois à basse et à haute température. Journal of Heat and Mass Transfer 1990, 33 (11), 2463-2478.

7. Prat, M. 2D modelling of drying of porous media: influence of edge effects at the interface. Drying Technology 1991, 9 (5), 1181-1208.

8. Turner, I.W. A two-dimensional orthotropic model for simulating wood drying processes. Applied Mathematical Modelling 1996, 20 (1), 60-81.

9. Chen, X.D. A discussion on a generalized correlation for drying rate modeling. Drying Technology 2005, 23 (3), 415-426.

10. Sander, A. Thin layer drying of porous mate-rials: selection of the appropriate model and relationships between thin-layer models parameters. Chemical Engineering and Processing 2007, 46, 13241331.

11. van Meel, D.A. Adiabatic convection batch drying with recirculation of air. Chemical Engineering Science 1958, 9, 36-44.

12. Saastamoinen, J.; Impola, R. Drying of biomass particles in fixed and moving beds. Drying technology 1997, 15 (6-8), 1919-1929.

13. Colin, J. Séchage en continu du bois énergie comme moyen de préconditionnement en vue de sa conversion thermochimique : approches expérimentale et numérique; $\mathrm{PhD}$ Report, AgroParisTech: Nancy, 2011.

14. Perré, P.; Turner, I.W. A 3-D version of TransPore: a comprehensive heat and mass transfer computational model for simulating the drying of porous media. International Journal of Heat and Mass Transfer 1999, 42 (24), 4501-4521.

15. Nganhou, J. Heat and mass transfer through a thick bed of cocoa beans during drying. Heat and Mass Transfer 2004, 40, 727-735.

16. Incropera, F.P.; DeWitt, D.P.; Brergman, T.L.; Lavine, A.S. Fundamentals of heat and mass transfer; 6th edition, 2006.

17. Salin, J.-G.; External heat and mass transfert. In Fundamentals of wood drying; Perré, P., Ed; A.R.BO.LOR.: Nancy, 2007; 175-201. 